Journal of Mechanical Engineering and Sciences

ISSN (Print): 2289-4659; e-ISSN: 2231-8380

Volume 12, Issue 4, pp. 4018-4029, December 2018

(C) Universiti Malaysia Pahang, Malaysia

DOI: https://doi.org/10.15282/jmes.12.4.2018.03.0349

\title{
Mechanical characteristics evaluation of dual phase and related hardening techniques on AISI 4340 steel
}

\section{B. M Gurumurthy, Sathyashankara Sharma*, U Achutha Kini, Ananda Hegde and Ajinkya Patil}

Department of Mechanical and Manufacturing Engineering, Manipal Institute of Technology, Manipal Academy of Higher Education, Manipal, India-576104

Phone: 919449330990; Fax: +Fax: 91-820-2571071.

*Email: ss.sharma@manipal.edu

\begin{abstract}
Steel has wide range of applications and is used in various machinery and general metallic components. Depending on the particular application, steels with tailorable and appropriate properties are used. This requires various methods which can be used to alter the properties based on the requirements. Generally, mechanical properties of the steel are improved by conducting the heat treatment processes. The aim of the present work is to experimentally investigate the effects of conventional heat treatments and special hardening techniques for dual phase structure on mechanical properties of AISI 4340 steel. The test specimens are machined as per ASTM standards and hardness, tensile, impact and microstructure analysis were carried out after the heat treatment processes. Dual phase heat treatment to obtain ferrite-bainite structure is performed by heating the as-bought specimen to the intercritical temperature for two hours followed by isothermal holding in fusible salt bath containing sodium nitrate and sodium nitrite at subcritical temperature for 30 minutes and cooling in air to room temperature. Similarly, ferritemartensite structure is obtained by air cooling after holding isothermally in the salt bath for 10 seconds. Ferrite-bainite steel was observed to be soft, whereas ferrite-martensite steel was relatively harder. Austempered steel has high toughness with optimum hardness and conventionally hardened steel is the hardest among all. Microstructure shows colony of bainite and martensite in ferrite matrix of ferrite-bainite and ferrite-martensite dual phase structures respectively. An increase in brittleness was observed with the increase in hardness due to the conventional hardening to display lesser impact strength compared to austempered steel.
\end{abstract}

Keywords: Bainite; austempering; microstructure; martensite.

\section{INTRODUCTION}

Heat treatment is a method of heating and cooling for different time intervals to improve the properties of the material [1-2]. During heat treatment of steel, type of phases, weight $\%$ of phases and grain size of the material may vary depending on the duration of treatment and cooling methods. Some of the properties may vary so that desired mechanical properties such as hardness, toughness, yield strength, ultimate tensile strength, Young's modulus, percentage elongation may be incorporated [3-5]. The most 
important heat treatment methods include normalizing, annealing, austempering, dual phase hardening, conventional hardening etc. Today, among different engineering materials available, steel is the most useful structural material for general applications because of its good mechanical properties. Annealing is the heat treatment wherein a material is softened, causing coarser grain structure with enhanced mechanical properties [6]. The process involves heating of steel to supercritical temperature and then cooling it slowly to yield diffusion controlled coarser or medium pearlite phase. Well distinguished lamellar colonies of ferrite-cementite (pearlite) are observed in the microstructure if the process variables are tailored suitably [7-8]. Annealing treatment is used where maximum ductility and appreciable level of tensile strength are required in engineering materials. In normalizing, the material is heated to the austenitic temperature range and critically cooled in air. This treatment is usually carried out to obtain fine pearlite colony followed by grain refinement, which results in better machinability due to the development of moderate strength and hardness levels [9-10]. The chemical composition, especially carbon content in the steel affects the strength and hardness [11].

In dual phase structures, two varieties ferrite-martensite (F-M) and ferrite-bainite (F-B) are possible. Dual phase of AISI 4340 steel results in moderate hardness with better toughness so that machinability of the component is improved. Dual phase structure provides balanced bulk properties required for better machining [12-13]. Water quenching yields excellent hardness with reduction in toughness. The property variation is due to the lattice distortion caused by the formation of supersaturated harder martensitic phase [14-15]. The austempering treatment results in uniform higher hardness with excellent toughness. The bainite structure formed in austempering is purely a diffusion controlled process and its hardness is in midway between the ultra-high hardened martensite and softer pearlite [16-17]. It is the substitute for conventional case hardening or surface hardening techniques. Dual phase steels have high resistance to corrosion compared to other structural steels [18].

\section{Properties and Application of AISI 4340 Steel}

Table 1 shows the chemical composition of AISI 4340 steel obtained from spectrometric analysis. It is a low alloy medium carbon steel, containing chromium, nickel and molybdenum. Chromium and molybdenum serve as ferrite stabilizers or carbide formers to improve hardness and wear resistance of the steel with better strength. Nickel is the strong austenite stabilizer which improves strength, toughness and hardenability properties. It has high good impact resistance and strength when grains are refined. Addition of molybdenum also prevents the steel from being susceptible to temper embrittlement. Nickel also improves the hardness, corrosion and wears resistance [19]. Chromium enhances corrosion and wear resistance [19]. The usage of these alloying elements, clearly demands different conditions where combination of properties is required.

AISI 4340 steel is a high tensile strength alloy steel renowned for its wear resistance properties and exactly fitting where high strength properties are required. Its application suits in high stress and severe temperature fluctuation environments. It is also one of the most usable ferrous metals in most of the applications, well demanded in power transmission system links and shafts, aircraft landing gears, heavy-duty axles, spindles and simple structural applications like, pins, studs, collets, bolts, couplings, sprockets etc. 
Table 1: Chemical composition of AISI 4340 steel (Spectrometric analysis)

\begin{tabular}{cc}
\hline Elements & Wt.\% \\
& \\
\hline Carbon & 0.40 \\
Silicon & 0.25 \\
Manganese & 0.70 \\
Nickel & 1.85 \\
Chromium & 0.80 \\
Molybdenum & 0.25 \\
Iron & 95.75 \\
\hline
\end{tabular}

\section{METHODOLOGY}

\section{Heat Treatment Procedure of Dual Phase}

Dual phase steel is a special variety of low or medium carbon hypoeutectoid steel obtained by controlled heat treatment to yield balanced amount of proeutectoid ferrite with martensite or bainite phase. Generally, before the treatment (as-bought condition) such steels consist of ferrite and cementite as equilibrium phases or fully hardened phases at room temperature. The ferrite phase is soft, cementite is hard and brittle and martensite is too brittle which makes machinability poor. The lamellar structure of ferrite and cementite present in steel at room temperature is termed as pearlite. Ferrite phase getting separated before pearlite formation is called pro-eutectoid ferrite. Pearlite contains well distributed lamellar ferrite and cementite as alternate layers.

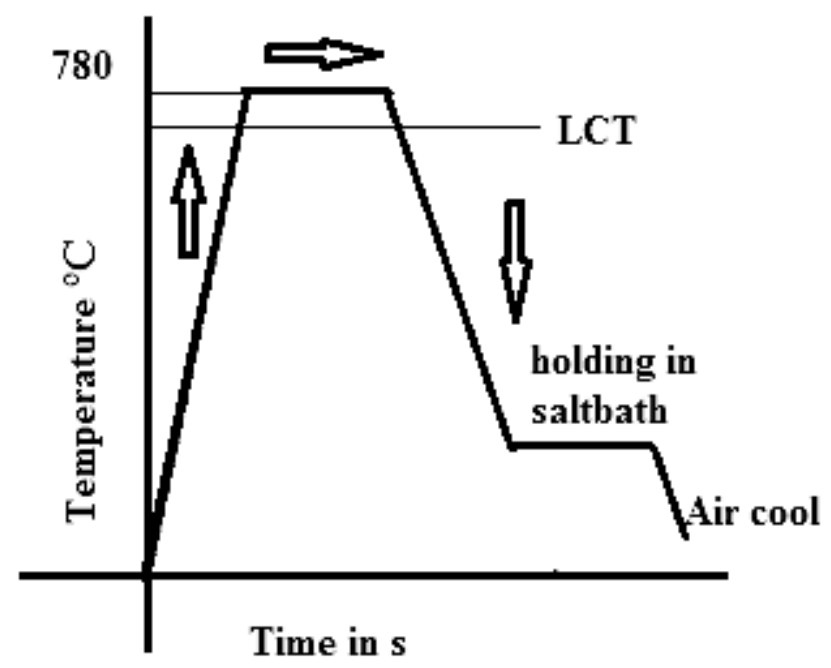

Figure 1. Dual phase heat treatment (Ferrite-Bainite).

\section{Ferrite - Bainite}

Figure 1 shows the methodology of dual phase heat treatment. As-bought specimens are heated to $780^{\circ} \mathrm{C}$ (intercritical temperature), held isothermally for two hours followed by quenching in salt bath comprising of sodium nitrate and nitrite (equal proportions by weight) isothermally at $350^{\circ} \mathrm{C}$ (subcritical temperature) for 30 minutes and cooling in air to room temperature to get the desired dual phase. 


\section{Ferrite - Martensite}

As-bought specimens are heated to $780^{\circ} \mathrm{C}$, isothermally are held at the same temperature for two hours followed by quenching in salt bath comprising of sodium nitrate and nitrite (equal proportions by weight) isothermally at $350^{\circ} \mathrm{C}$ for 10 seconds and cooling in air to room temperature for the ferrite-martensite dual phase.

\section{Austempering}

Specimens are heated to a temperature of $900^{\circ} \mathrm{C}$ for two hours followed by quenching in salt bath comprising of sodium nitrate and nitrite (equal proportions by weight) isothermally at $350^{\circ} \mathrm{C}$ for 30 minutes and cooling in air to room temperature. This treatment refines the pearlite colony with finer lamellar ferrite and cementite.

\section{Water Quenching}

It is also known as conventional hardening. Specimens are heated to a temperature of $900^{\circ} \mathrm{C}$ for two hours followed by water quenching to get the martensite phase at the room temperature.

\section{TEST SPECIMENS AND MATERIAL}

\section{Impact Specimen}

Commercially available $16 \mathrm{~mm}$ diameter AISI 4340 rod is procured from the market. First, material is cut into $60 \mathrm{~mm}$ long pieces using band saw. Drilling is carried out to make the hole at one end in order to hold the work piece in tail stock. Turning is carried out in the engine lathe to prepare the specimen as per the dimension. Shaping is carried out to obtain $10 \times 10 \mathrm{~mm}^{2}$ square cross section. Specimens are prepared as per ASTM E23-020 standard-Type A (Figure 2) [20]. V-notch is cut on the square work piece using shaper and is rounded off.

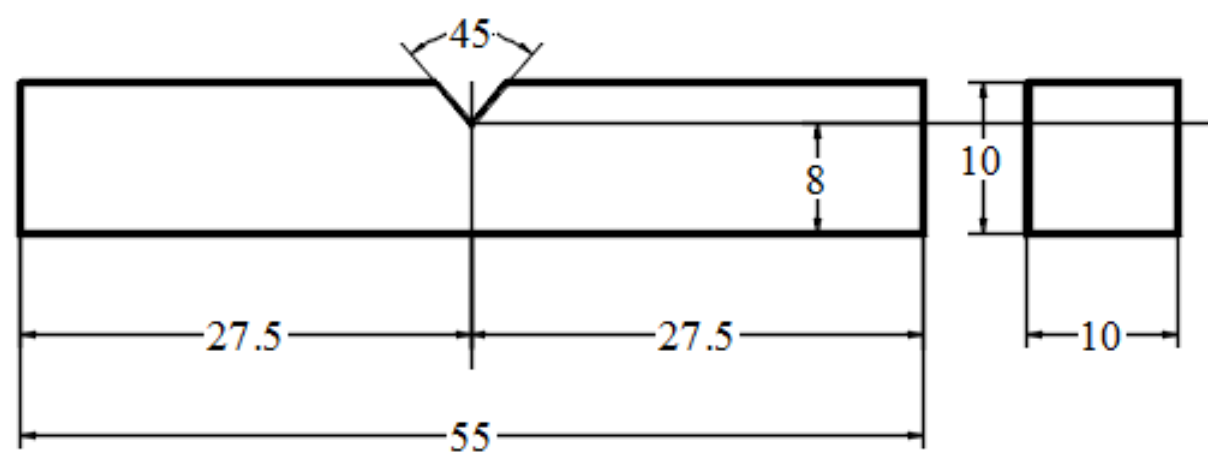

Figure 2. Dimensions of impact test specimen (all dimensions are in $\mathrm{mm}$ ).

\section{Hardness Specimen}

First, cylindrical specimen is cut in to $25 \mathrm{~mm}$ length using band saw and turned to reduce its diameter to $15 \mathrm{~mm}$. The ends are smoothened by facing operation and length is reduced to $25 \mathrm{~mm}$. Specimen is prepared as per ASTM E18-02 standard (Figure 3) [21]. 


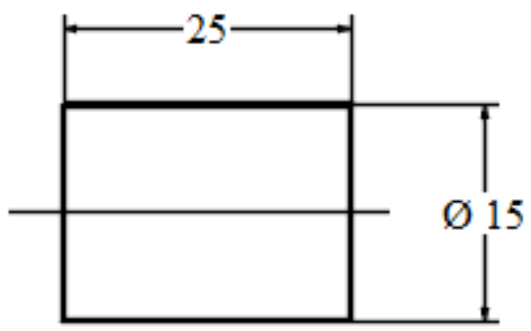

Figure 3. Hardness specimen (all dimensions are in $\mathrm{mm}$ ).

\section{Tensile Specimen}

The commercially available $10 \mathrm{~mm}$ diameter rod is cut into $30 \mathrm{~mm}$ length cylindrical pieces using band saw. The required length of the specimen is obtained by facing operation on Engine lathe. Step turning is carried out as shown and edges are rounded off to finish the job. The ASTM E8M standard tensile specimen used in the study is shown in Figure 4 [22].

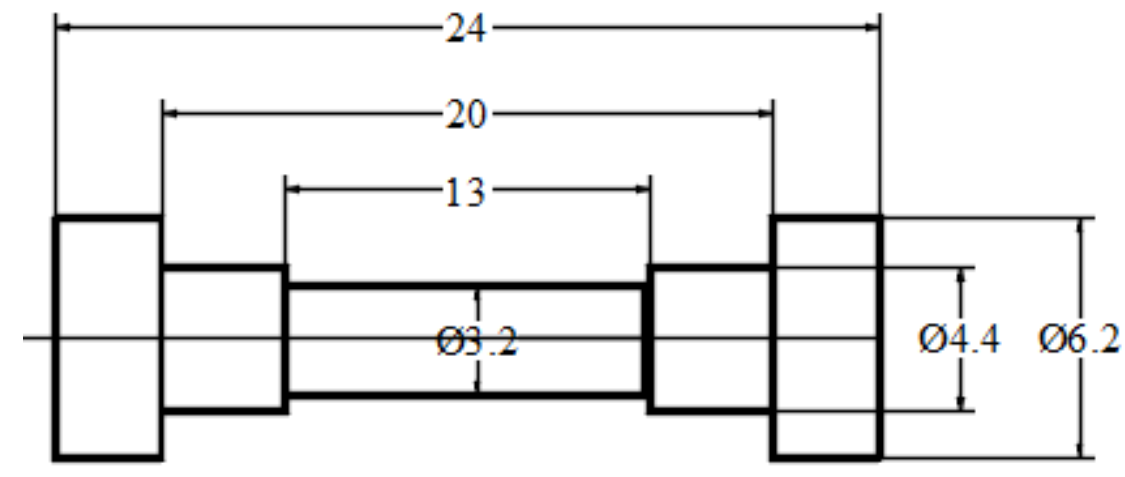

Figure 4. Tensile specimen (all dimensions are in $\mathrm{mm}$ ).

\section{Impact Test}

\section{EXPERIMENTAL DETAILS}

Charpy impact machine is used to find the impact resistance of the specimen. The impact test is carried out under the maximum load condition and the pendulum is released to strike the specimen with impact load. The energy absorbed before failure is noted. Total of three trials are conducted and recorded.

\section{Hardness Test}

Matzusawa micro Vickers hardness tester (model- MMT X 7A) is used to determine the hardness of the specimen. It is placed on the hardness testing fixture and magnification is set to 400X. Micro-indentation is made on the surface of the specimen by applying 100 gf for 15 seconds. With the help of eye piece, the length of the diagonals of the indentation is measured.

\section{Tensile Test}

Computer controlled Tensometer (kudale instrument) is employed for tensile test. Specimen is clamped between the jaws and then load is applied till it fails. The load verses displacement graphs are analyzed and corresponding values of the percentage elongation and ultimate tensile strength are recorded. Yield strengths are calculated from the load 
versus displacement graphs. The average values of three trails conducted during the experiments are considered as the result.

\section{Microstructure Study}

Inverted metallurgical microscope is employed for obtaining the microstructure at $200 \mathrm{X}$ magnification. Specimens prepared as per the dimension specified in ASTM E18-02, are finished using emery papers in the order of $1 / 0,2 / 0,3 / 0$ and $4 / 0$, to obtain the smooth surface [23]. The specific order of emery papers is used to remove all the scratches on the specimen. The final polishing to mirror finish is performed on disc polisher mounted with velvet cloth using diamond paste. Before mounting the specimen on holder for capturing the images, it is etched with 5\% Nital (Ethanol $100 \mathrm{ml}$ and Nitric acid 1-10 ml mixture), rinsed with cold water and dried.

\section{RESULTS AND DISCUSSION}

\section{Charpy Impact Test}

The impact energy values in Joules obtained by three trials are recorded and the bar chart is drawn (Figure 5). The impact energy absorbed is the measure of toughness of the specimen. The result shows that austempered material has excellent toughness value followed by F-B dual phase. The excellent toughness of austempered is due to the lower bainitie phase containing strained finer ferrite with cementite [11]. The well distributed randomly oriented fine ferrite and cementite phases surrounded by enormous dislocation density are responsible for the excellent toughness [24]. Surprisingly, F-B dual phase shows almost the same toughness values as that of austempered. This may be due to the combined effect of transformed bainite with well distributed finer proeutectoid ferrite phase. The specimens containing martensite with and without ferrite shows lower impact energy. It is due to the behavior of brittle martensite.

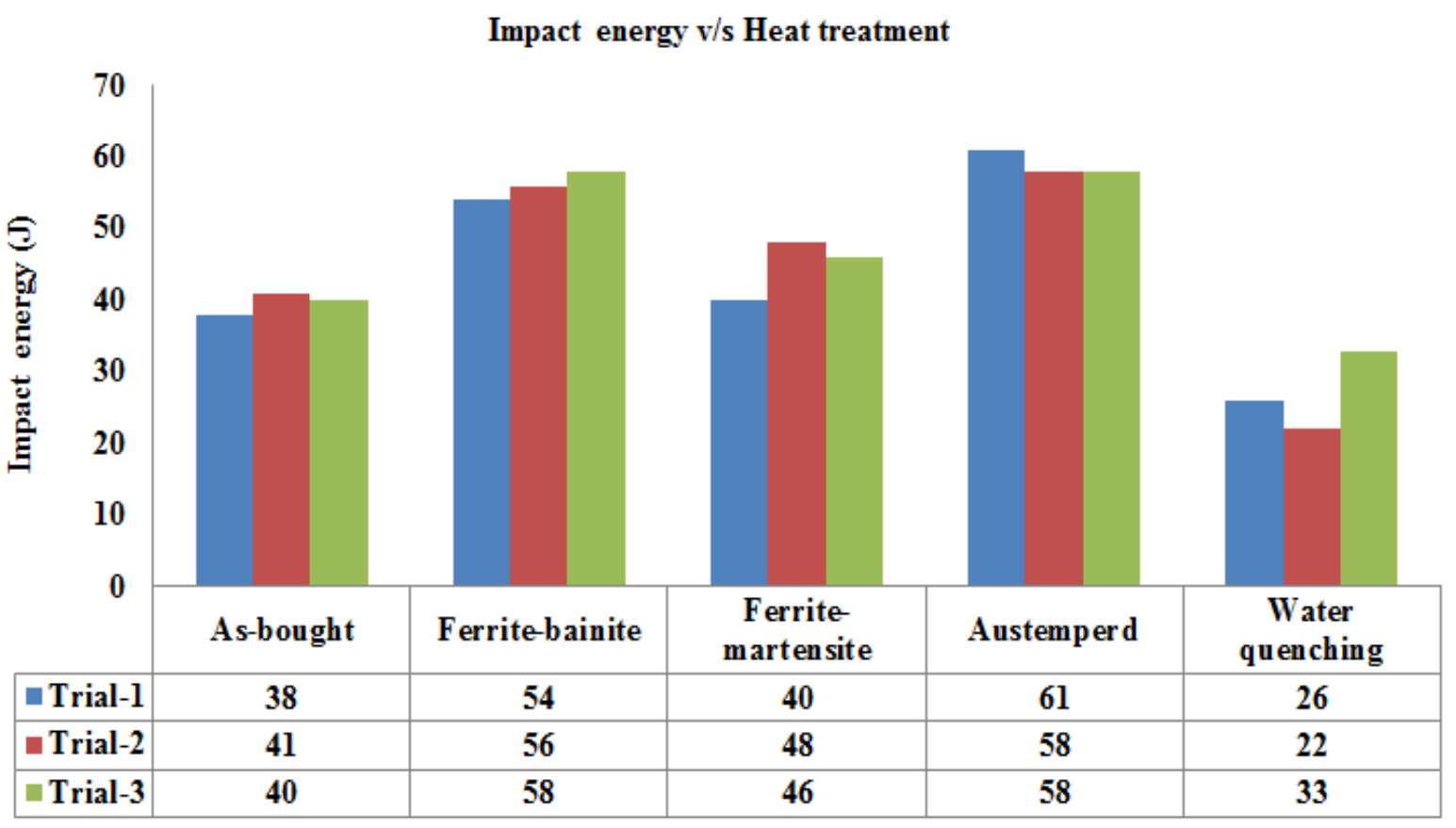

Figure 5. Impact energy versus heat treatments. 
As-bought specimen shows moderate good toughness values compared to water quenched and it justifies that the as-bought steel is normalized steel one with fine pearlite structure.

\section{Hardness Test}

The hardness of bainite is in between that of ferrite and martensite [18]. Hardness of asbought and F-B dual phase specimen is poor and at par with each other. This may be due to the behavior of ferrite (higher ductility, poor hardness) dominated phase. F-M dual phase hardness is slightly poor than austempered one (Figure 6). Since ferrite phase quantity is dominated in F-M dual phase, the specimen hardness is not the replica of hardest martensite phase (water quenched). Water quenched shows excellent surface hardness compared to the other heat treatment conditions due to the formation of supersaturated martensite phase coupled with enormous amount of crystal defects it is the hardest phase that one can observe in steel [5].

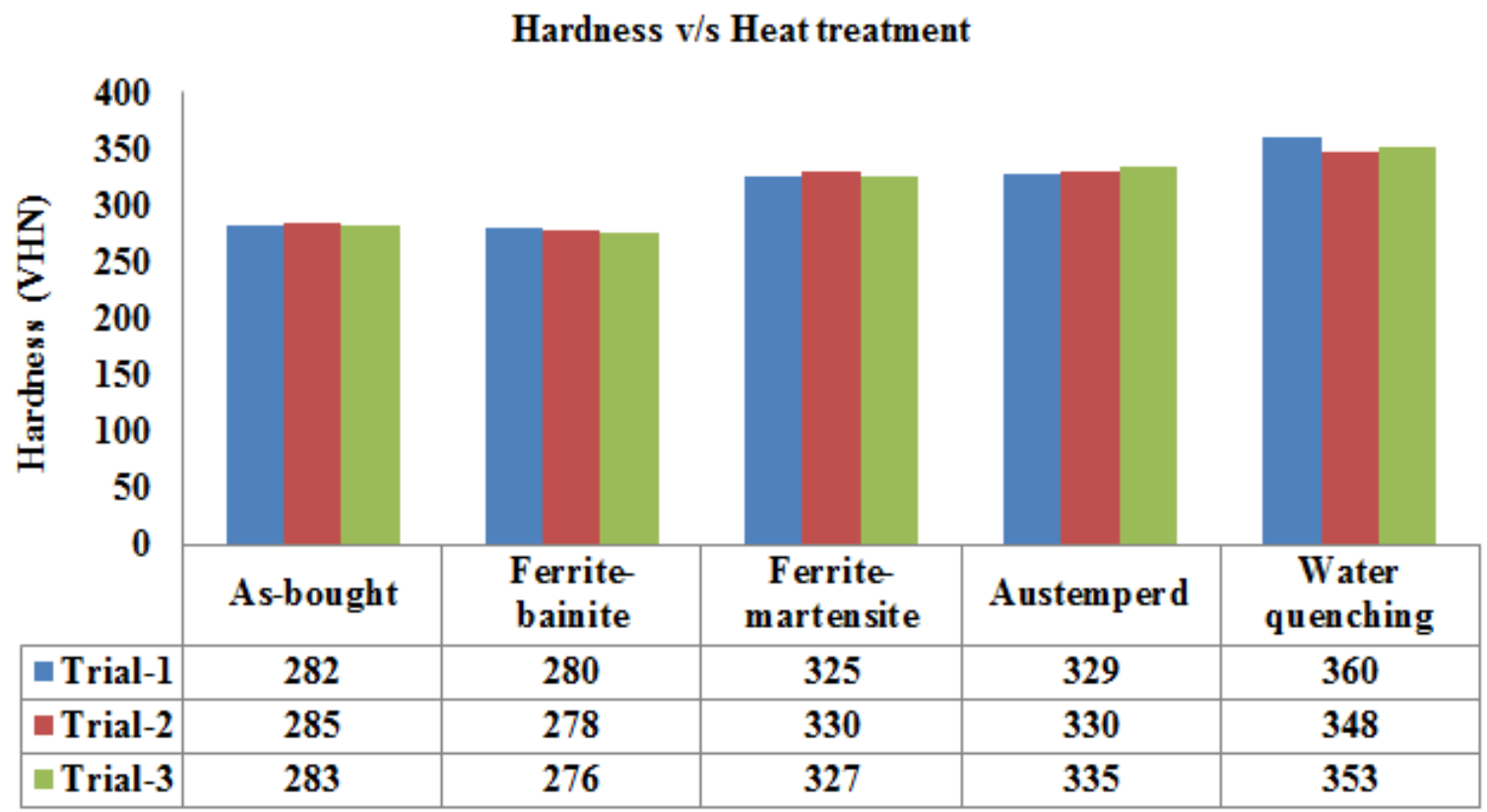

Figure 6. Hardness versus heat treatments.

\section{Tensile Property}

The tensile property of martensite and bainite are almost similar and is superior compared to ferrite structure [18]. The yield strengths of F-M and water quenched are comparable whereas as-bought shows least. Yield strengths of F-M dual phase and F-B dual phase are 0.7 to 0.6 times as that of fully austempered, whereas water quenched shows the value in between that of austempered and F-M dual phase. The reduction in strength of asbought specimen may be due to the formation of dendritic segregation [11]. Ultimate tensile strengths of water quenched and F-M dual phase are almost equal and greater than F-B dual phase and lesser than fully austempered (Figure 7). 


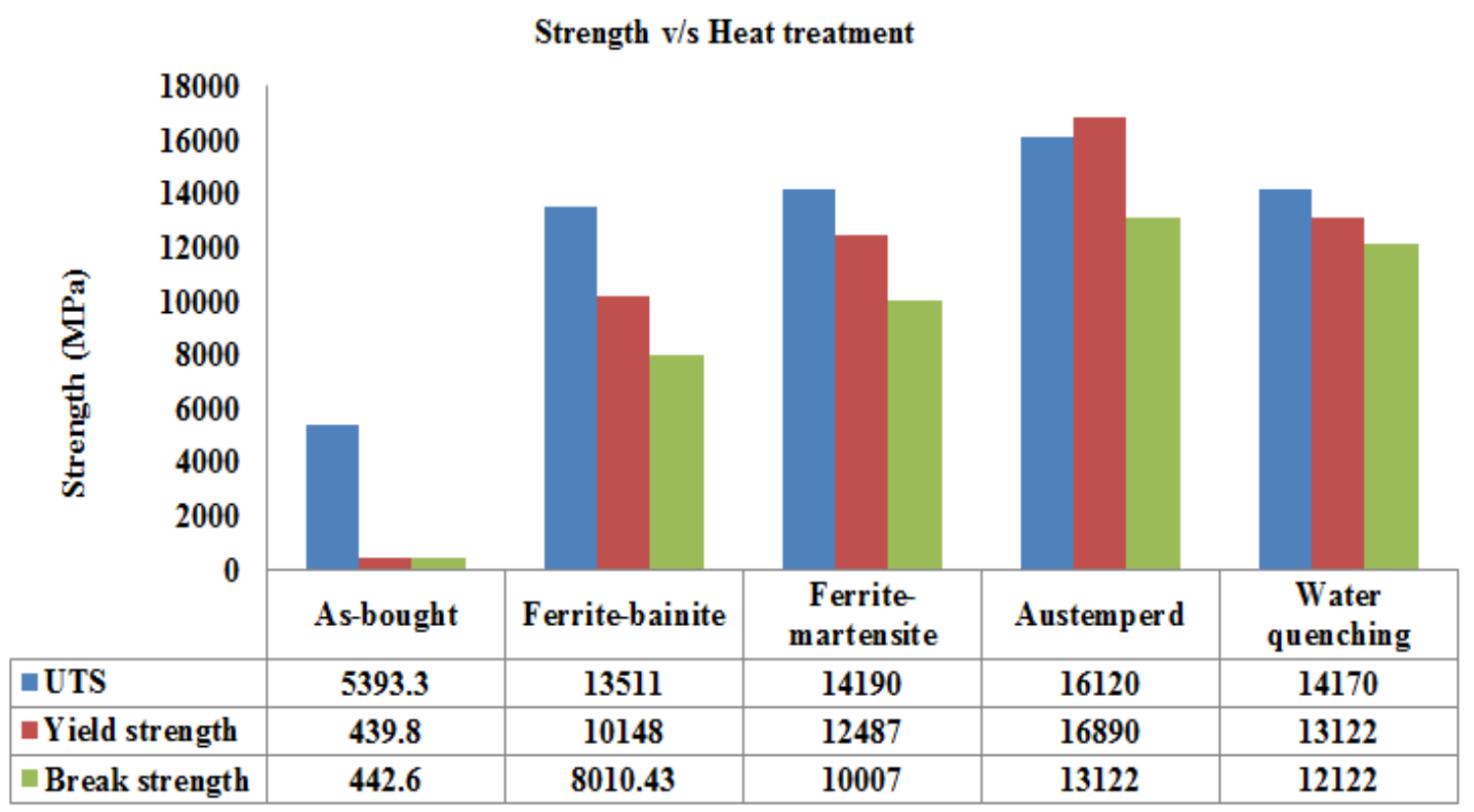

Figure 7. Tensile strength versus heat treatments.

Ferrite is softer phase and has got higher ductility [4]. Marensite is brittle phase, poor in ductility. Bainite phase strength is higher, ductility is moderate. Accordingly, F-B dual phase shows excellent ductility and is $40 \%$ greater than F-M dual phase specimen. Austempered ductility value is in between F-B and F-M dual phase specimens. Figure 8 shows that as hardness and strength decrease, ductility increases.

\section{Elongation v/s Heat treatment}

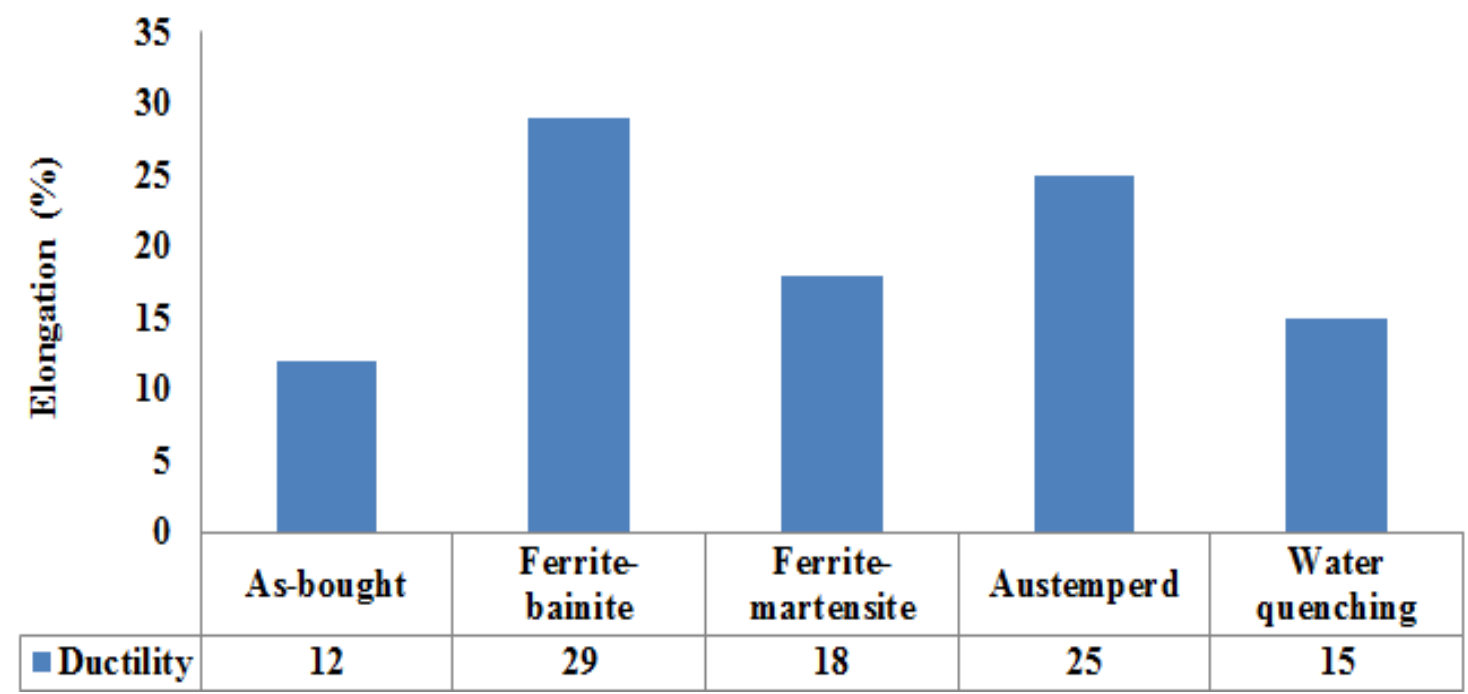

Figure 8. Elongation (\%) versus heat treatments.

Microstructure of as-bought, F-B and F-M dual phase specimens at 200X magnification are shown in Figures 9(a), (b) and (c) respectively. As-bought microstructure shows fine pearlite colonies and proeutectoid ferrite phases (Figures 8(a)). The F-B and F-M dual phase specimens show islands of bainite and martensite phases respectively in the ferrite 
matrix shown in Figures 8 (b) and (c), respectively. Randomly oriented cementite and ferrite discrete phases are seen in fully austempered and plate like parallelly orientated martensite in water hardened specimens (Figures 8(d) and (e)).

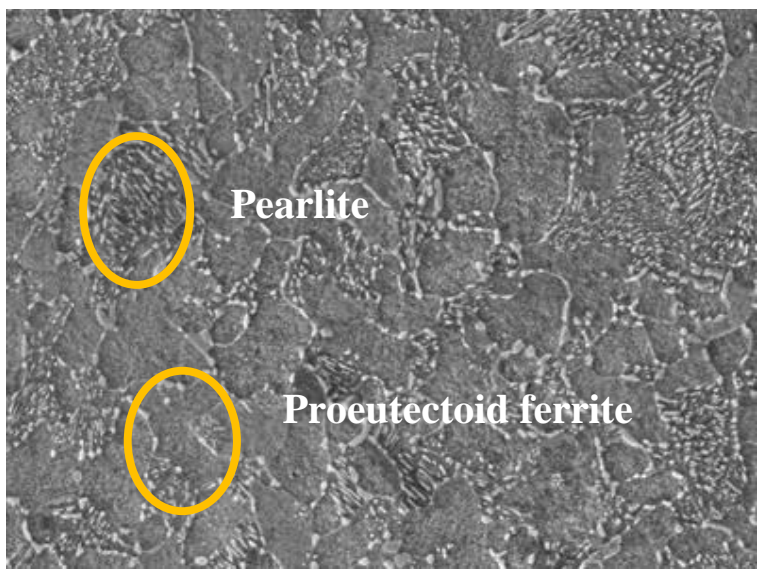

(a)

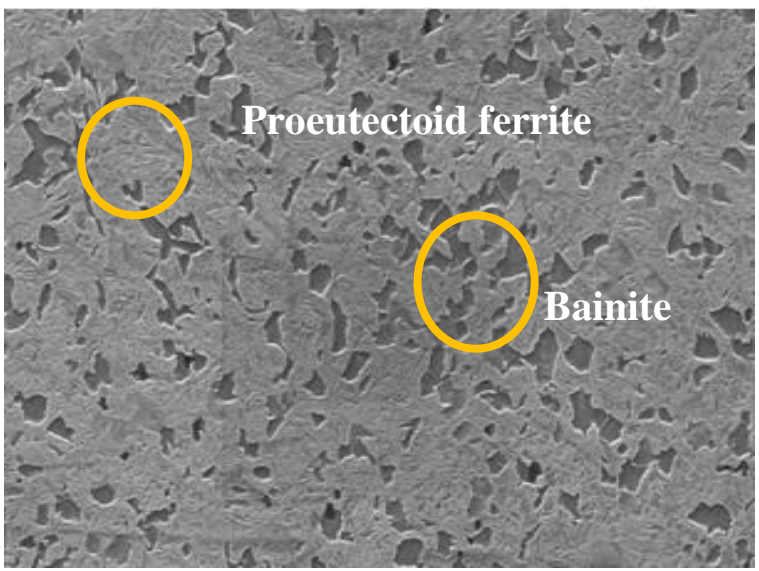

(b)

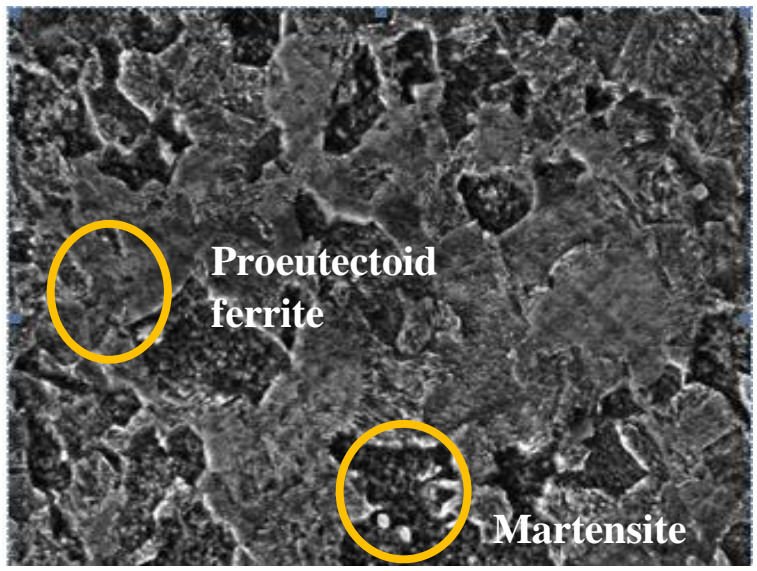

(c) 


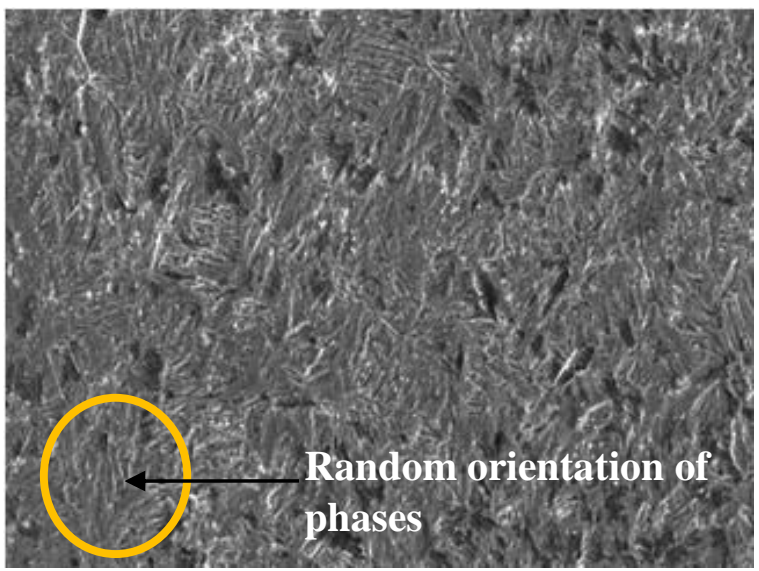

(d)

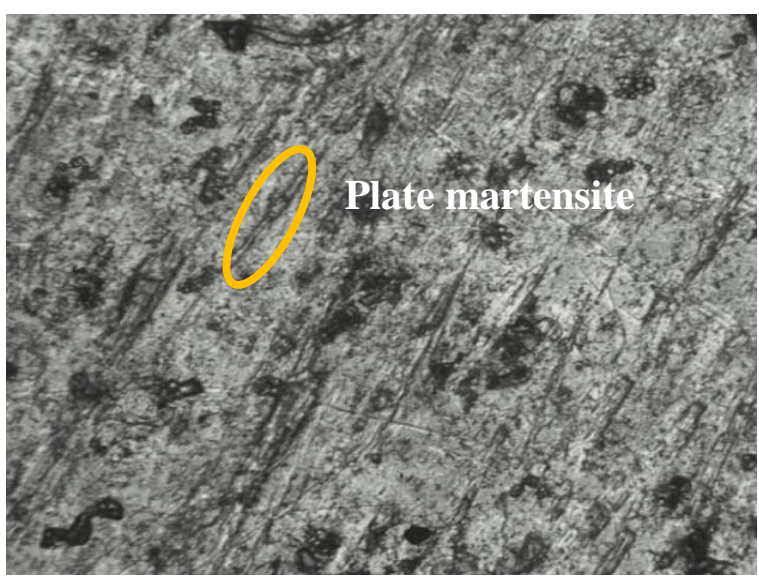

(e)

Figure 9. Microstructure of specimen (a) As-bought (b) F- B dual phase (c) F-M dual phase (d) Austempered (e) Water quench at 200X.

\section{CONCLUSIONS}

The steel is successfully heat treated with considerable alterations in properties without any change in chemical composition and dimension. Following conclusions are arrived from the experiments. The austempered and F-B dual phase specimens show almost similar values of toughness and are little higher than F-M phase. Water quenched specimen shows excellent hardness followed by F-M dual phase and austempered in the next decreasing sequential positions respectively. Yield strength of F-M dual phase and F-B dual phase is 0.7 and 0.6 times respectively as that of fully austempered one, whereas water quenched shows closer values to austempered one. Ultimate tensile strengths of water quenched and F-M dual phase are equal and slightly greater than F-B dual phase and lower than fully austempered one. F-B dual phase shows excellent ductility and is $40 \%$ greater than that of F-M dual phase specimen. The F-B and F-M dual phase specimens show islands of bainite and martensite phases in the ferrite matrix. Random orientation of cementite and ferrite discrete phases are seen in fully austempered and plate like parallelly orientated martensite in water quenched specimens. 


\section{REFERENCES}

[1] Asadi ZS, Mahboubi F. Effect of component's geometry on the plasma nitriding behavior of AISI 4340 steel. Materials and Design. 2012;34:516-21.

[2] Celik A, Karadeniz S. Improvement of the fatigue strength of AISI 4140 steel by an ion nitriding process. Surface and Coatings Technology. 1995;72:169-73.

[3] Yerra S, Martin G, Veron M, Brechet Y, Mithieux J, Delannay L. Ductile fracture initiated by interface nucleation in two-phase elastoplastic systems. Engineering Fracture Mechanics. 2013;102:77-100.

[4] Abdalla AJ, Hein LRO, Pereira MS, Hashimoto TM. Mechanical behaviour of strain aged dual phase steels. Materials Science and Technology. 1999;15:116770.

[5] Erdogan M, Priestner R. Effect of martensite content, its dispersion, and epitaxial ferrite content on Bauschinger behaviour of dual phase steel. Journal of Materials Science and Technology. 2002;18:369-376.

[6] Calcagnotto M, Adachi Y, Ponge D, Raabe D. Deformation and frcature mechanisum in fine and ultrafine grinde ferrite/martensite dual phase steels and the effect of aging. Acta Materialia. 2011;59:658-670.

[7] Ramazani A, Schwedt A, Aretz A, Prahl U, Bleck W. Characterization and modelling of failure initiation in DP steel, Computational Materials Science. 2013;74:35-44.

[8] Ramazani A, Abbasi M, Kazemiabnavi S, Schmauder S. Larson R, Prahl U. Development and application of a microstructure-based approach to characterize and model failure initiation in DP steels using XFEM. Materials Science and Engineering A. 2016;660:181-194.

[9] Hozumi G, Yoshufumi A. Effect of varying load on wear resistance of carbon steel under unlubricated conditions. Wear. 2003;254:1256-1266.

[10] Yan QZ, Liu WM, Qun JX. Comparative study of the tribological properties of various modified mild steels under boundary lubrication condition. Wear. 2005;38:508-514.

[11] Anijdan SHM, Vahdani H. Room-temperature mechanical properties of dual phase steels deformed at high temperatures. Materials Letter. 2005;9:1828-1830.

[12] Larour P, Verleysen P, Bleck W. Influence of uniaxial, biaxial and plane strain pre-straining on the dynamic tensile properties of high strength sheet steels. Journal of Physics. 2006;134:1085-1090.

[13] Pradeep LM, Kishore, Satish V, Kailas. Influence of surface texture on coefficient of friction and transfer layer formation during sliding of pure Mg pin on EN 8 steel plate. Wear. 2006;261:578-591.

[14] Anand PM, Effects of microstructure and experimental parameters on high stress abrasive wear behaviour of a $0.19 \mathrm{wt} \%$ Carbon dual phase steel. Tribology International Journal. 2007;40:490-497.

[15] Sarwar M, Ahmad E, Qureshi KA, Manzoor. Influence of epitaxial ferrite on tensile properties of dual phase steel. Materials Design. 2007;28:335-40.

[16] Suleyman G, Atilla T. Influence of straining and aging on the RT mechanical properties of dual phase steel. Materials and Design. 2008;29: 1914-1918.

[17] Gunduz S, Demir B, Kacar R. Effect of aging temperature and martensite by volume on strain aging behaviour of dual phase steel. Iron making and Steel making. 2008;23:63-68. 
[18] Gurumurthy BM, Sharma SS, Kini UA. Ferrite-martensite dual phase treatment of AISI 1040 steel and mechanical characterization. Key Engineering Materials. 2017;748: 280-283.

[19] Atcharawadi T, Chatdanai B. Tribological and corrosion behaviors of carburized AISI 4340 steel, Japanese Journal of Applied Physics. 2015;55:193-198.

[20] ASTME E23 - 07A. An American National Standard Standard Test Methods for Notched Bar Impact Testing of Metallic Materials. 2007.

[21] ASTME 18 - 02. Standard Test Methods for Rockwell Hardness and Rockwell Superficial Hardness of Metallic Materials. 2002.

[22] ASTM E8/E8M - 13. Standard Test Methods for Tension Testing of Metallic Materials. 2011.

[23] Ravichandran M, Naveen SA, Vignesh U. Investigation on TIG welding parameters of 2205 duplex stainless steel, International Journal of Automotive and Mechanical Engineering. 2017;14:4518-4530.

[24] Sujit KJ. Investigation of micro-structure and mechanical properties of three steel alloys. International Journal of Automotive and Mechanical Engineering. 2017;14:4315-4331. 